DOI: 10.20472/IAC.2018.038.038

JISOO SON

Sungkyunkwan University, Korea, Republic of

\title{
THE IMPACTS OF DOMESTIC POLITICAL ECONOMIC STRUCTURES ON SUSTAINABLE TRADE AGREEMENTS BETWEEN ASYMMETRIC COUNTRIES
}

\begin{abstract}
:
This paper examines how the domestic political economic structures influence the bargaining power of small economies facing market dominant large trade partner. Through the analysis of the incentive compatibility conditions of small economies and large economies facing different political stances of domestic interest groups, we demonstrate that when the politically influential interest groups of large economies take the political stance supporting free trade regime, small economies' bargaining power can be improved. This result stems from the reduced equilibrium transfer from small economies to keep the trade equilibrium as a stable equilibrium due to the pro-free trade political pressures imposed by the interest groups of large economies. This result provides good theoretical insights on why most small economies are so eager to keep close connection with the interest groups in large economies
\end{abstract}

\section{Keywords:}

Stable trade agreement, Domestic political interest groups, Bargaining power of small economies, equilibrium transfer to satisfy incentive compatibility conditions

JEL Classification: F51, F53, D47 


\section{Introduction}

The 'new nationalism' has been widely spread throughout the world with bitter regrets by marginalized groups and countries on the negative side effects of uncoordinated globalization lately. Brexit, the Britain's exit from European Union, is under progress after the shocking decision of the UK voters supporting for the Brexit, and the US is about to retreat from NAFTA with the strong policy drive by the Trump regime that believes the protection is the last resort of the regime which was inaugurated by the fury of the unskilled white blue color workers.

In addition to the increasing protective pressures imposed by the domestic interest groups damaged by the globalization and free trade, the multilateral trade regime under the governance of WTO (World Trade Organization) has been in decades of deadlock since the collapse of multilateral market liberalization efforts under DDA (Doha Development Agenda) regime. The major factors that collapsed DDA are considered to be the uncompromisable conflicts and differences in positions between advanced economies and developing and underdeveloped economies. Developing and underdeveloped economies, mostly small economies, considered advanced economies, usually large economies, are trying to exercise market powers to extract most of rents from free trade leaving almost nothing for small developing economies. To be specific, large advanced economies demanded the liberalization of service markets of developing economies in addition to the further market liberalization of manufactured product markets with no exception. Moreover, large developed economies refused removing subsidies for their agricultural sectors, and kept quite reserved approaches in providing technical aids to developing economies eventually driving out small developing economies from the negotiation table.

After the failure of DDA negotiation, it has been considered that mechanism design for the multilateral trade regime that satisfy incentive compatibility conditions of large economies and small economies simultaneously is the starting point to establish stable multilateral trade regime. Due to the fact that market powers are usually commanded by the large advanced economies, it is essential to find a path that satisfy the incentive compatibility conditions of small developing economies with enhanced bargaining power commanded by the small developing countries.

Motivated by these backgrounds that urgently require to develop an international trade regime that satisfy incentive compatibility conditions for small developing countries and bargaining power of developing economies, this paper examines the impacts of political influences of domestic interest groups on the stable international trade regime. With increasing political influences commanded by the domestic interest groups, we study how the different political stances of interest groups influence the bargaining power of small economies by examining how the incentive compatibility conditions of both large economies and small economies are affected by the political influences of the interest groups. More specifically, we focus on how the equilibrium amount of the 
transfer that makes the trade agreement as a stable equilibrium is affected by the political influences of the interest groups.

Through the above analysis of the incentive compatibility conditions of small economies and large economies facing different political stances of domestic interest groups, we demonstrate that when the politically influential interest groups of large economies take the political stance supporting free trade regime, small economies' bargaining power can be improved. This result stems from the reduced equilibrium transfer from small economies to keep the trade equilibrium as a stable equilibrium due to the pro-free trade political pressures imposed by the interest groups of large economies. This result provides good theoretical insights on why most small economies are so eager to keep close connection with the interest groups in large economies.

The impacts of the bargaining power asymmetry in the international trade agreement have been widely studied since the seminal paper by Mayer (1981) and Kennan and Riezman (1988). Earlier studies have shown that asymmetry in each country's ability to manipulate the terms of trade through tariffs determine the bargaining power in the trade negotiation and the equilibrium level of transfers between negotiating parties of the trade agreements. Since this manipulative ability largely depends on the relative size of trading partners, the terms of trade gains for a larger country from imposing tariffs can dominate the loss from its domestic distortions caused by a tariff war with a smaller country. This will lead to the situation where the larger country will prefer a tariff war to free trade with its smaller trading partner, as in Mayer (1981) and Kennan and Riezman (1988). A Pareto-improving trade agreement is still possible, however, if the large country's tariffs are replaced with an efficient transfer mechanism. McLaren (1997) and Park (2000) consider this possibility based on Ricardian model of bilateral trade between a small and a large country.

Based on the Ricardian model, Park (2000) examines self-enforcing trade agreements in a repeated relationship by focusing on subgame perfect trade agreements where deviations are punished by a permanent reversion to a static Nash tariff war between countries. Park (2000) identifies several factors in the structure and environment of agreements which may affect the outcome of trade negotiations between countries of asymmetric size focusing on how autarky punishments work when there is a deviation from agreements. Park (2000) argues that an autarky punishment may benefit the small country facing a larger trade partner since it expands the power of self-enforcing trade agreements in a direction that is favorable to the small country. Therefore, autarky punishment might induce countries of asymmetric move towards higher level of cooperation in trade negotiation.

The major difference of this paper from the earlier literatures comes from that this paper examines how different types of political economic features determine stable equilibrium trade agreements, which was not considered seriously in earlier literatures. 
As already discussed, this paper demonstrates that when the politically influential interest groups of large economies take the political stance supporting free trade regime, small economies' bargaining power can be improved.

\section{The Model}

The basic set-up for the static game follows a standard Ricardian model of bilateral trade. Consider trade between a small and a large country, where each country has $m$ and $\mathrm{M}(>\mathrm{m})$ units of labor, respectively. There are two kinds of goods, $x$ and $y$, that require one unit of labor to produce one unit of them in each country, except that producing one unit of $x$ requires only $1 / \alpha$ units of labor in the small country. For preferences, all the consumers in the two countries have the following CES utility functions:

$U\left(c_{x}, c_{y}\right)=\left(c_{x}^{(\sigma-1) / \sigma}, c_{y}^{(\sigma-1) / \sigma}\right)^{\sigma /(\sigma-1)}$

where $c^{x}$ and $c^{y}$ represent the consumption of the two goods, and $\sigma(>0)$ is the elasticity of substitution. As long as $\sigma<\infty$, the autarky price of $y$ in terms of $x$ will be $\sigma(>1)$ for the small country and 1 for the large country, implying the small country's comparative advantage in the production of $\mathrm{x}$. The terms of trade $P_{y} / p_{x}$ and this will be $(1+T)$. Consider that the large country can change the terms of trade in its favor by imposing a tariff, but the small country cannot affect the terms of trade by its trade policy choices.

Given the set-up described above, two kinds of Nash equilibria exist in the static game: one with trade and the other without trade.

\subsection{The interior Nash equilibrium}

In interior Nash equilibrium with positive trade, the small country will set t equal to 0 . However, the large country can change the terms of trade in its favor by raising its tariff rate. It can be shown that there exists a critical level of the elasticity of substitution (denoted by $\sigma^{M}$ ) such that iff $\sigma \leq \sigma^{M}$, the large country has a strong enough incentive to push the terms of trade $\left(P_{y} / P_{x}\right)$ to be equal to the small country's autarky price ratio $(\alpha)$. Thus, all the gains from trade are transferred to the large country with the interior Nash equilibrium tariff pair $\left(t^{n}, T^{N}\right)=(0, \alpha-1)$.

From the world welfare point of view, there is no production distortion associated with the large country's positive tariffs in the interior Nash equilibrium. However, it is important that the large country's tariff distort the consumption decision of the small country by creating a difference in the countries' local price ratios. This inefficiency creates the possibility of a mutually beneficial trade agreement between the two countries of asymmetric size. 


\subsection{The autarky equilibria}

The small country's domestic price ratio, $p_{y} / p_{x}=(1+\mathrm{T})$, and any tariff pair $(\mathrm{t}, \mathrm{T})$ with $(\mathrm{t}, \mathrm{T})>(\alpha-1, \alpha-1)$ can be supported as a Nash equilibrium yielding an autarky state. If either country imposes a tariff rate greater than $\alpha-1$, its trading partner will be indifferent in choosing any non-negative tariff rate, since trade will be prohibited in any event. Therefore, neither country has an incentive to deviate from any tariff pair with $(\mathrm{t}, \mathrm{T})>(\alpha-1, \alpha-1)$, satisfying the definition of Nash equilibrium.

\section{Trade agreements}

In this section, I will consider the possibility of trade agreements between the small and the large country that can correct the inefficiencies embodied in the Nash equilibrium. Also, I consider the possibility that the two countries adopt tariffs from the set of autarky Nash equilibria as well as the possibility that they revert to the interior Nash equilibrium as a means of punishing deviations from the trade agreements. As I discussed above, due to the inefficiency associated with the large country's positive tariff, it is possible to negotiate an efficient trade agreement under which both countries are better off than in the interior Nash equilibrium.

\subsection{Efficient policy combinations}

Recalling that price level and welfare level of both the small country and the large country, it is illustrated in Fig. 1. by using CES utility function. $W^{A}$ and $w^{A}$ represent respectively that welfare levels for the large and the small country relative to their autarky welfare levels.

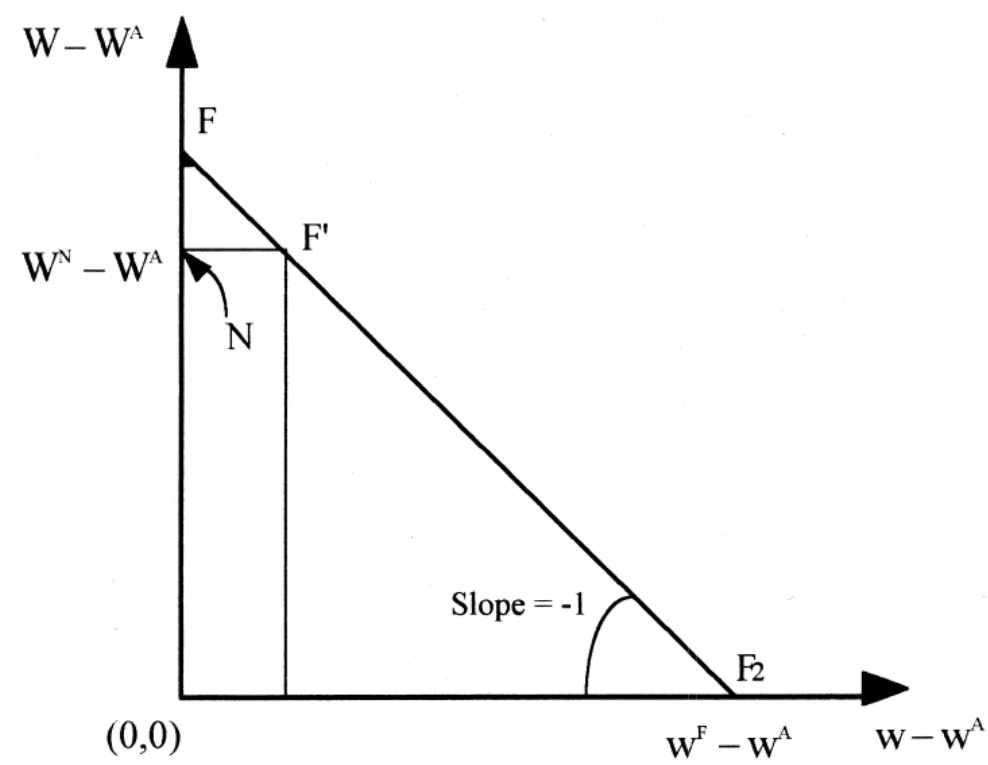


Given the CES utility function, each country's level of welfare $(w, W)$ is a linear function of its level of income measured at local prices; thus, I can formulate utilities in the two counries as functions of their tariff rates, respectively denoted by $\mathrm{w}(\mathrm{t}, \mathrm{T})$ and $\mathrm{W}(\mathrm{T}, \mathrm{t})$, as follows:

$$
\begin{aligned}
& \mathrm{w}(\mathrm{t}, \mathrm{T})=w(p, i)=i /\left(1+p^{1-\alpha}\right)^{1 /(1-\sigma)} \quad \text { and } \\
& \mathrm{W}(\mathrm{T}, \mathrm{t})=W(P, I)=I /\left(1+P^{1-\alpha}\right)^{1 /(1-\sigma)}
\end{aligned}
$$

Fig.1. depicts the interior Nash welfare levels by the point labeled $\mathrm{N}$ for the case there $\sigma \leq \sigma^{M}$. Given this point $\mathrm{N}$, it is evident that any point on the segment FF' is preferred by both countries to the interior Nash equilibrium, implying the possibility of mutually beneficial trade agreements between the small and the large country.

In addition, there is an alternative way for two countries to achieve points along the efficiency locus $F_{2} F$ in Fig.1. This suggests two possible forms that trade negotiations between small and large countries could take: move along the efficiency locus $F_{2} F$ in Fig.1. by negotiating over the size of the direct lump-sum international transfers, or they could negotiate over tariff reductions to reach to an efficient level of trade by trade agreements.

In principle, these two approaches to efficient trade agreements could yield identical outcomes for the two countries. However, in practice, a variety of issues may arise across these two kinds of agreements that could affect the feasible outcomes of the negotiation in each case. To explore this possibility, I will consider the internal political pressure from special interest group and use this to increase the smaller country's bargaining power as a tactic in trade agreement negotiations.

\section{Stable trade agreement under domestic political pressures by the interest groups}

Stable international trade agreement should satisfy incentive compatibility conditions of both large economies and small economies that guarantee the higher payoffs from keeping the trade agreement than the payoffs from deviating to non-cooperative trade policies in an infinitely repeated trade negotiation game as defined as follows:

$\frac{1}{1-\delta}\left(w^{F}-s\right) \geq w^{F}+\frac{1}{1-\delta} w^{P}:$ Incentive Compatibility condition for small economies $\frac{1}{1-\delta}\left(W^{F}+s\right) \geq W\left(T^{N}, 0\right)+s+\frac{\delta}{1-\delta} W^{P}:$ IC condition for large economies

where $s$ denotes the amount of transfer from small economies to large economies to keep IC conditions to be satisfied. 
The above IC conditions can be rearranged for the transfer as follows:

$s \leq \delta\left(w^{F}-w^{P}\right): I C_{S}$

$s \geq \frac{(1-\delta) W\left(T^{N}, 0\right)-W^{A}+\delta W^{P}}{\delta}: I C s$

When the interior Nash punishment scheme is introduced if the trade partner deviates to the non-cooperative trade regime, the welfare level from the interior Nash equilibrium can be defined as follows:

$w^{N}=w^{A}=w^{P}$ and $W^{P}=W^{N}$

Then, the equilibrium level of transfer satisfying both incentive compatibility conditions can be redefined as follows:

$\frac{W^{N}-W^{A}}{\delta} \leq s \leq \delta\left(w^{F}-w^{A}\right)$

Now, we consider the impacts of domestic political pressures imposed by the interest groups on the equilibrium trade agreement. If the politically influential interest groups in the large economy take a political position supporting protective trade policies, the large economy's payoffs from punishment scheme can be defined as follows:

$W^{P}=W^{N}+\beta$

where $\beta>0$ if the large country's interest group supports protective trade policies, and $\beta<0$ if the large country's interest group supports free trade policies.

Integrating the political impacts of the interest groups of large economies into the equilibrium level of transfer satisfying both incentive compatibility conditions, we obtain the following condition:

$$
\frac{W^{N}-W^{A}+\delta \beta}{\delta} \leq s \leq \delta\left(w^{F}-w^{A}\right)
$$

The above result implies that the equilibrium level of transfer from small economies is increased if the interest groups in the large economy support protective trade policies deteriorating the bargaining power of the small economies. On the other hand, if the interest groups of the large economy support free trade policies, the equilibrium amount of transfer from small economy is decreased improving the bargaining power of the small economy. This result is summarized as follows. 
Proposition 1. When the politically influential interest groups of the large economy supports free trade policies, the equilibrium level of transfers from small economy to support incentive compatibility conditions of the large economy is decreased enhancing the bargaining power of the small economy.

When the small country's trade policy is also affected by the politically influential interest groups in the small economy, the payoffs from the punishment scheme for the small economy can be defined as follows:

$w^{P}=w^{A}+\gamma$

where $\gamma>0$ if the small country's interest group supports protective trade policies, and $\gamma<0$ if the small country's interest group supports free trade policies.

When the political influences of the interest groups of both large economy and small economy are considered, the equilibrium level of transfer satisfying both incentive compatibility conditions is defined as follows:

$\frac{W^{N}-W^{A}+\delta \beta}{\delta} \leq s \leq \delta\left(w^{F}-w^{A}-\gamma\right)$

The above equilibrium transfer condition implies that when politically influential interest groups of both small and large economies exercise the political pressures on the trade policies, the equilibrium transfer from the small economy to support the incentive compatibility conditions depends on the relative strength of the political influence the interest groups from both countries. When both interest groups support protective policies, if small economies' interest groups are more strongly organized with $\beta<\delta \gamma$, the equilibrium transfer is decreased with the bargaining power of the small economy enhanced. The result is summarized as follows:

Proposition 2. When both small and large economies' interest groups are active in exercising political influences on the trade policies, the impacts on the trade equilibrium depend on the relative strength of the political influences of two interest groups. If $\beta<\delta \gamma$, the bargaining power of the small economy is increased.

Large country's trade policies tend to be determined with longer perspective while small countries' policies might be determined with short time horizon in general. Considering the asymmetry of the discount factors of large country and small country additionally, the equilibrium level of transfers satisfying both incentive compatibility conditions is defined as follows:

$\frac{W^{N}-W^{A}+\delta_{l} \beta}{\delta_{l}} \leq s \leq \delta_{s}\left(w^{F}-w^{A}-\gamma\right)$ 
The comparative statics of the above equilibrium conditions with respect to the different level of discount factors, $\delta_{l}$ and $\delta_{s}$, shows that when the large country's trade policies are determined with longer time horizon, the equilibrium transfer is decreased enhancing the bargaining power of the small economy. On the other hand, when the time horizon of the small country is shorter with lower discount factor, the equilibrium transfer is reduced with the higher bargaining power of the small economy. ${ }^{1}$ The result is summarized in the following proposition.

Proposition 3. When asymmetry of the discount factors are considered, if the large economy's trade policies are determined with longer time horizon, the bargaining power of the small economy is enhanced. On the other hand, when the small country takes a short-term approach in the trade policies, her bargaining power can be increased.

These results provide theoretical insights on why small countries are making active efforts to keep good connection with the interest groups in the large economies. In addition, the results show that politically active interest groups in both small and large economies can exert significant influences on the trade agreement reflecting the relative strength of interest groups in both countries. Moreover, the features of political regime in terms of time preference play an important role in determining the relative bargaining power of small economies.

\section{Concluding remarks}

This paper examined the impact of the politically influential domestic interest groups on the equilibrium trade agreement and the bargaining power of small economies. The analysis on the equilibrium amount of transfer from the small economy to the large economy to satisfy the incentive compatibility condition of the large country to abide by the cooperative trade regime produced the following results: When the interest groups of large country supports free trade policies, the bargaining power of the small country is enhanced. Moreover, when the interest groups of the small country is also politically active in exercising their influences on trade policies, their impacts on the equilibrium trade agreement depends on the relative strength of two interest groups. Finally, the time preferences of both countries matter eventually determining the relative bargaining power of both large and small countries.

These results provide insights on why small countries exert significant efforts in establishing effective connection with politically influential interest groups and lobbying groups. Moreover, understanding the time preferences of each trade regime in terms

1 The comparative statics of the equilibrium conditions for the transfer is given as follows:

$$
\frac{\partial\left(\left(W^{N}-W^{A}+\delta_{l} \beta\right) / \delta_{l}\right)}{\partial \delta_{l}}=-\frac{W^{N}-W^{A}}{\delta_{l}^{2}}<0
$$


of discount factors is essential for the efficient positioning in the trade negotiation strategies for successful trade negotiation.

Nonetheless, the understanding of the impacts of politically influential interest groups on the trade agreement can be deepened with the introduction of more explicit political economic model articulating the concrete path of the political influences commanded by the interest groups, which would be the tasks for the future extension of this study.

\section{References}

Kennan, J., Riezman, R., 1988. Do big countries win tariff wars? International Economic Review 29(I), 81-85.

Meyer, W., 1981. Theoretical considerations on negotiated tariff adjustments. Oxford Economic Paper 33, 135-153.

McLaren, J., 1997. Size, sunk costs, and Judge Bowker's objection to free trade. American Economic Review 87(3), 400-420.

Jee-Hyeong, Park., 2000, International trade agreements between counties of asymmetric size. Journal of International Economics 50(2000), 473-495.

International Theories of cooperation among nations ; Strength and weakness. World Politics, Vol. 44, No.3(Apr., 1992), pp. 466-496. 